\title{
Validation of Total Mercury in Marine Sediment and Biological Samples, Using Cold Vapour Atomic Absorption Spectrometry
}

\author{
Ahmed Abou Elezz ${ }^{1, *(D)}$, Hassan Mustafa Hassan ${ }^{1}$ (D), Hamood Abdulla Alsaadi ${ }^{1}$, Ahmed Easa ${ }^{2}$, \\ Saeed Al-Meer ${ }^{2}$, Khaled Elsaid ${ }^{3}$, Zafar Khan Ghouri ${ }^{3, *(1)}$ and Ahmed Abdala ${ }^{3, * \text { (D) }}$ \\ 1 Environmental Science Center (ESC), Qatar University, P.O. Box 2713, Doha, Qatar; \\ hassan.hassan@qu.edu.qa (H.M.H.); halsaadi@qu.edu.qa (H.A.A.) \\ 2 Central Laboratory Unit, Qatar University, P.O. Box 2713, Doha, Qatar; ahmedaali@qu.edu.qa (A.E.); \\ salmeer@qu.edu.qa (S.A.-M.) \\ 3 Chemical Engineering Program, Texas A\&M University at Qatar, P.O. Box 23874, Doha, Qatar; \\ Khaled.elsaid@qatar.tamu.edu \\ * Correspondence: a.hassan@qu.edu.qa (A.A.E.); zafar_khan.ghouri@qatar.tamu.edu or \\ zafarkhanghouri@hotmail.com (Z.K.G.); Ahmed.abdala@qatar.tamu.edu (A.A.) \\ Received: 2 July 2018; Accepted: 16 August 2018; Published: 23 August 2018

\begin{abstract}
A method for the measurement of total mercury (T-Hg) in environmental samples using cold vapour atomic absorption spectrometry (CV AAS) has been validated yielding a dynamic range $(0.04-10.00 \mu \mathrm{g} / \mathrm{kg})$ and high certified reference material (CRM) recovery $(>90 \%)$. The validation was carried out according to International Union of Pure and Applied Chemistry (IUPAC) validation and Eurachem Guides. A freeze-dried and homogenised sample was weighed and then digested using Suprapur acids $\left(\mathrm{HNO}_{3}, \mathrm{H}_{2} \mathrm{SO}_{4}\right.$, and $\left.\mathrm{HF}\right)$ with potassium dichromate solution in a hot block digestion system. A calibration curve was constructed $\left(\mathrm{R}^{2}>0.999\right)$. Two CRMs (Marine Sediment Reference Material (PACS-3) and Trace Elements in Muscle Tissue (Trace Elements and Methylmercury in Mussel Tissue (NIST2976)) were utilised for quality assurance and control. The limit of quantification (LOQ) calculated as $0.04 \mu \mathrm{g} / \mathrm{kg}$, and uncertainty (U) calculated as $2 \%$. The obtained results showed the suitability of this method for direct mercury measurement in environmental samples. Additionally, the proficiency of this method was recognised by accreditation under the standard of International Organization for Standardization (ISO/IEC 17025:2017) for competence of testing and calibration laboratories.
\end{abstract}

Keywords: total mercury; validation method; IUPAC; absorption spectrometry; quantification

\section{Introduction}

Mercury is recognised as one of the most hazardous environmental pollutants. It is released into the environment by anthropogenic and natural sources such as: volcanoes; industrial runoffs from contaminated soils; as well as gold and ore mining. According to the U.S. Environmental Protection Agency (US EPA), concentrations of total mercury (T-Hg) in biological samples are usually less than $0.1 \mathrm{mg} / \mathrm{kg}$ [1], while levels in sediment vary depending on the state of pollution of the area under study, the proper assessment of which necessitates the analysis of a large number of samples. Thus, there is a need for a robust, validated and inexpensive analytical method. Moreover, these methods should match the levels of total $\mathrm{Hg}$ that are hopefully, expected to be low.

The most frequently used protocols to determine total $\mathrm{Hg}$ in some biological samples employ atomic absorption spectrometry [2] and inductively coupled plasma mass spectrometry (ICP-MS) [3]. However, these methods require an additional sample preparation step that, significantly increases the 
analysis time and may be a source of contamination. Furthermore, there are some issues encountered when ICP-MS is used in the determination of total $\mathrm{Hg}$. The use of the mercury analyser instrument model-AULA-254 is one of the recent alternatives to perform the T-Hg determination. Its uses include the evaluation of various environmental samples such as water, soils, sludge, and the analysis of foodstuffs and biota.

The analysis principle is based on a continuous flow method, where the mercury within the sample is converted into its elemental state with the aid of a reducing agent. The mercury is then stripped and carried to an optical cell, where the determination is performed by UV absorption at a wavelength of $253.7 \mathrm{~nm}$. This technique is more commonly known as cold vapour atomic absorption spectrometry (CV AAS) [4].

In general, sensitive analytical methods are required for validation of traces of mercury in sediment and biota, since its concentration may be too low to be analysed by conventional methods.

The study aimed to develop and validate a robust method used to prepare and analyse various environmental samples. The novelty of the proposed method lies in its capability to estimate $\mathrm{T}-\mathrm{Hg}$ content in a variety of environmental samples (water, sediment, and biota) following set sample preparation steps.

The quality of the proposed method has been checked by performing a complete method validation using set International Union of Pure and Applied Chemistry (IUPAC) criteria and employing two CRMs, its application to real samples has been illustrated by processing several environmental samples from the marine environment.

\section{Material and Methods}

\subsection{Apparatus, Chemicals, and Reagents}

Cold vapour atomic absorption spectrometry was utilised for $\mathrm{T}-\mathrm{Hg}$ measurement, using an AULA-254 Gold (Mercury instruments GmbH Analytical Technologies, Karlsfeld, Germany), equipped with an electrodeless low-pressure mercury UV-absorption source set at a wavelength of $253.7 \mathrm{~nm}$ and running AULA-254 software (AULA-WIN, TM based) [5] for data processing. Argon 99.999\% (Buzwair Scientific and Technical Gases, Doha, Qatar) and high-quality type 2 deionised water ( 18 M $\Omega \mathrm{cm})$ from Thermos Barnstead system (GENPURE UV-TOC Life Technologies Ltd. Paisley, UK) were used. Other reagents such as Suprapur nitric acid (65\%), sulfuric acid (98\%), hydrofluoric acid (40\%), an oxidising reagent (Potassium dichromate, EMSURE ${ }^{\circledR}$ ACS), potassium permanganate (EMSURE ${ }^{\circledR}$ ACS, Reag), hydroxylamine hydrochloride (99.999\% trace metals basis), and tin-II-chloride ( $\geq 99.99 \%$ trace metals basis) were all obtained from Merck (Boston, MA, USA). Certified reference material (CRM) NIST-2976 (mussel tissue (trace elements and methylmercury), certified value: $0.061 \pm 0.0036 \mathrm{mg} / \mathrm{kg}$ ) were sourced from the National Institute of Standards and Technology (Gaithersburg, MD, USA). CRM PACS-3 (Marine Sediment Reference Material for Trace Metals and other Constituents), certified value: $2.98 \pm 0.36(\mathrm{mg} / \mathrm{kg})$ was purchased from the National Research Council Canada (Ottawa, ON, Canada). Mercuric nitrate standard was used as a stock calibration standard $(1001 \pm 2 \mathrm{pg} / \mathrm{mL}, 2 \%$, nitric acid in low TOC water $(<50 \mathrm{ppb}))$.

\subsection{Sample Preparation}

The Environmental Science Centre has adapted the following procedure in preparing samples for $\mathrm{T}-\mathrm{Hg}$ analysis. Approximately $0.1 \pm 0.05 \mathrm{~g}$ of freeze-dried and homogenised sample was transferred into a $50 \mathrm{~mL}$ Teflon tube, $1 \mathrm{~mL} \mathrm{HF}$ was added together with $5 \mathrm{~mL} \mathrm{HNO}_{3}$, and $3 \mathrm{~mL} \mathrm{H}_{2} \mathrm{SO}_{4}$ (Suprapur, Merck) to decompose and release matrix-bound mercury. The sample was then digested using a hot block set at $125^{\circ} \mathrm{C}$ for $12 \mathrm{~h}$ with the cap closed to reduce mercury loss by volatilisation. After complete digestion, indicated by a clear solution, the tube was left to cool to room temperature after which $1 \mathrm{~mL}$ of resulting mixture was transferred into a $50 \mathrm{~mL}$ measuring flask together with $2 \mathrm{~mL}$ potassium dichromate, and the final volume made up to the mark with reagent water. This constitutes 
the sample solution. Other protocols employ different sample preparation techniques that may require different sample weights, utilise different digestion acids and other digestion apparatus [6,7].

\subsection{Sample Analysis}

Ten $\mathrm{mL}$ of the prepared sample was introduced into the AULA-254 for analysis. The process is automated in which the sample is oxidised, heated, reduced and finally analysed for T-Hg.

Moisture content determination of the environmental sample matrices was also carried out by a drying procedure $\left(105 \pm 2{ }^{\circ} \mathrm{C}\right.$ for $\left.48 \mathrm{~h}\right)$ using a validated and ventilated oven. Ten samples were used to calculate the mean moisture content with minimum sample mass $1 \mathrm{~g}[8,9]$.

\section{Results and Discussion}

\subsection{Method Validation}

The method was validated according to the IUPAC guideline, and Eurachem Guides, which include characterisation of selectivity, trueness, recovery, precision (repeatability \& intermediate precision), limit of detection, limit of quantitation, linearity, range, and ruggedness [10,11]. The uncertainty of measurement was also calculated. The validation process was performed by analysing two different CRM matrices (PACS-3 and NIST-2976).

\subsubsection{Selectivity}

Selectivity is the degree to which a method can quantitatively select a distinct analyte in the presence of other analytes that may interfere with the analyte under investigation. Matrix effect was investigated by analyzing two CRMs; each has a different matrix (muscle tissue and marine sediment). Interferences can result from anions or matrix. The main interference anion is chloride and sulfide will be absorbed in the same wavelength of mercury causing a positive interference. The matrix effects can be of two types; mask effects or background effects. Chloride and sulfide anions can be eliminated by adding potassium permanganate [12,13].

Two distinct peaks were observed from the CRMs previously described in Section 3.1, for low and high levels of T-Hg with no significant interference from other constituents within the CRMs with recovery $>90 \%$. Figure 1 shows a typical of mercury at high (A) and low (B) levels $(7$ and $0.01 \mu \mathrm{g} / \mathrm{L}$ respectively) and a blank $(\mathrm{C})$ with low noise and low background (absorbance $<0.001)$. The only T-Hg peak appears at the same retention time $(\sim 60 \mathrm{~s})$ in the, from two prepared CRM samples containing other constituents.

\subsubsection{Trueness}

Trueness relates to the systematic error of a measurement system and to how the mean value of replicate measurements are close to the true value. Eight measurements from two CRMs were analysed for bias; Table 1 shows the results of the trueness test on different days. The data obtained shows a relative bias of $4 \%$, and $-9 \%$ for NIST2976 and PACS3 respectively (Table 2).

Table 1. The mean of eight replicate results of two different matrices (biota and marine sediment certified reference materials (CRMs)).

\begin{tabular}{cccccc}
\hline CRM & $\boldsymbol{n}$ & NIST-2976 & Ref. Vale & PACS-3 & Ref. Vale \\
\hline Mean value $(\mathrm{mg} / \mathrm{Kg})$ & 8 & $0.058 \pm 0.002$ & $0.061 \pm 0.004$ & $2.87 \pm 0.15$ & $2.98 \pm 0.36$ \\
\hline
\end{tabular}


Table 2. Zeta results of two different matrices CRM.

\begin{tabular}{cc}
\hline CRM(NIST-2976) & CRM(PACS-3) \\
\hline Bias $=-0.002$ & Bias $=-0.28$ \\
\hline Relative bias $=-4 \%$ & Relative bias $=-9 \%$ \\
\hline$S D=0.006$ & $\mathrm{u}(\mathrm{lab})=0.12$ \\
\hline $\mathrm{u}(\mathrm{ref})=0.002$ & $\mathrm{u}(\mathrm{ref})=0.25$ \\
\hline $\mathrm{z} \mid$ & $\mathrm{z} \mathrm{z} \mid$ \\
\hline \multicolumn{2}{c}{ SD: Standard deviation. }
\end{tabular}
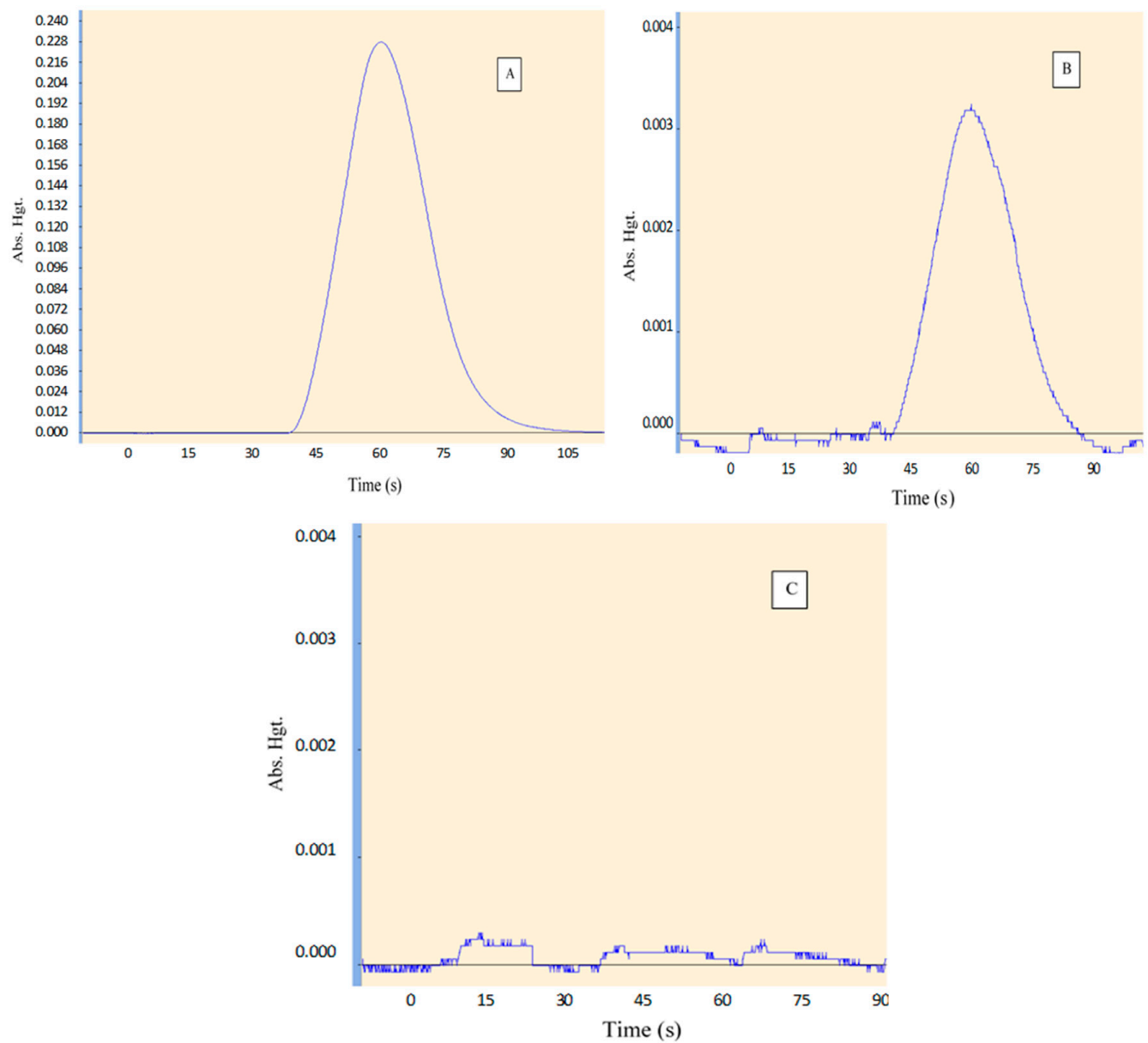

Figure 1. Spectrum of total mercury ( $\mathrm{T}-\mathrm{Hg}$ ) analysis in two matrix reference materials at two different levels (high (A), low (B)) and blank sample noise background (C).

The relative bias was calculated from Equation (1). Zeta score Equation (2) considers the reference material and the lab uncertainty. Table 2 shows that the relative bias in both CRMs (9).

$$
\begin{gathered}
\text { Bias } \%=\frac{\left(X_{l a b}-X_{r e f}\right)}{X_{r e f}} \times 100 \\
Z=\frac{\left(X_{l a b}-X_{r e f}\right)}{\sqrt{\left((S D)^{2}+\left(u_{r e f}\right)^{2}\right)}}
\end{gathered}
$$

where:

$X_{l a b}=$ Mean of Measurement 
$X_{\text {ref }}=$ Mean of certified value

$S D=$ Standard deviation of replicates

$u_{\text {ref }}=$ Standard certified uncertainty

\subsubsection{Recovery and Matrix Effects}

Determination of T-Hg in environmental samples directly is problematic due to a matrix effect. The determination of mercury in these matrices (especially sediments and soil) accurately often requires decomposition of the matrix and conversion of all mercury forms to $\mathrm{Hg}(\mathrm{II})$, which can be reduced quantitatively to $\mathrm{Hg}^{0}$ [14].

High and low levels of concentration and different matrices were used for recovery calculations. Table 3 provides a comparison between our proposed method and traditional methods $[7,15]$ of total mercury analysis by using CV-AAS and comparable matrices. Our method represents a high average $\%$ recovery (>95\%) in both CRM matrices and relative standard deviation (RSD) less than or equal 5\%.

Table 3. Comparison between our proposed method and traditional methods for total mercury analysis using cold vapour atomic absorption spectrometry (CV AAS) and comparable matrices.

\begin{tabular}{|c|c|c|c|c|c|c|}
\hline Method & Matrix & Certified Value ( $\mu \mathrm{g} / \mathrm{kg}$ ) & Avg. Measured Value $(\mu \mathrm{g} / \mathrm{kg})$ & Avg. \% Rec & No. of Samples & RSD \\
\hline \multirow[t]{2}{*}{ EPA-7474 } & NIST 8406 SED & 60 & 62 & $103 \%$ & 70 & $15 \%$ \\
\hline & NIST 1566 Oyster tissue & 84 & 81 & $97 \%$ & 72 & $15 \%$ \\
\hline \multirow{2}{*}{ EPA-7473 } & Estuarine Sediment NIST SRM 1646 & 63 & 75 & $119 \%$ & $\mathrm{~N} / \mathrm{A}$ & $3 \%$ \\
\hline & Oyster Tissue NIST SRM 1566a & 64 & 68 & $106 \%$ & N/A & $3 \%$ \\
\hline
\end{tabular}

\subsubsection{Precision}

The precision character of measurement includes repeatability and intermediate precision. The RSD of replicates was used to evaluate the mean concentration of independent samples, and it shall not exceed 10\% [16,17], and its calculated as (Equation (3)):

$$
\mathrm{RSD}=\frac{(S t d)}{\text { Mean }} \times 100
$$

Repeatability

Random error calculated from five repeated spiked blanks at three different levels $(0.2,2,8 \mu \mathrm{g} / \mathrm{L})$ through one day of analysis was used to assess the repeatability. Table 4 shows the RSD obtained from all CRMs replicates less than 10\%, and full fill the criteria [16].

Table 4. Repeatability results in $\mu \mathrm{g} / \mathrm{L}$ of five replicates at three different levels during one day.

\begin{tabular}{cccc}
\hline & Level $1(0.2 \mu \mathrm{g} / \mathrm{L})$ & Level $2(2 \mu \mathrm{g} / \mathrm{L})$ & Level $3(8 \mu \mathrm{g} / \mathrm{L})$ \\
\hline Mean & 0.165 & 2.001 & 8.027 \\
SD & 0.008 & 0.030 & 0.077 \\
RSD & $5 \%$ & $2 \%$ & $1 \%$ \\
\hline
\end{tabular}

\section{Intermediate Precision}

Random error converts to systematic error over an extended period [17]. Intermediate precision is used to represent this type of error produced as a result of different operators, lab conditions, and batches of chemical reagents for an extended period. Table 5 shows the RSD obtained from eight CRMs (PACS-3 and NIST2976) analysis results performed over a periodic interval was less than 10\% and full fill the criteria [17]. 
Table 5. Intermediate precision concentration in $\mathrm{mg} / \mathrm{kg}$ of eight CRM replicates between $15 \mathrm{March}$ and 17 April.

\begin{tabular}{cccc}
\hline CRM & Mean $/ \mathbf{m g} / \mathbf{k g}$ & St. Dev. & RSD \\
\hline PACS3 & 2.784 & 0.143 & $5.10 \%$ \\
NIST2976 & 0.062 & 0.003 & $4.80 \%$ \\
\hline
\end{tabular}

RSD: Relative standard deviation.

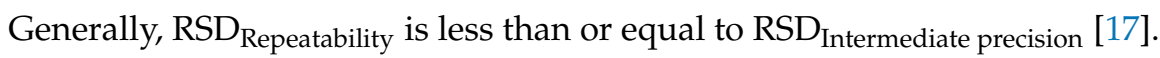

\subsubsection{Limit of Detection and Limit of Quantitation}

The detection limit is defined as "the lowest concentration of an analyte in the test sample that can be reliably distinguished from zero". While the LOQ, defined as "the concentration below which the analytical method cannot operate with acceptable precision". Low-level mercury spiked blanks concentration $(0.01 \mu \mathrm{g} / \mathrm{kg})$ were used to calculate the limit of detection (LOD), and limit of quantitation (LOQ) form a series of ten replicate $[11,16]$. The LOD was calculated as $0.01 \mu \mathrm{g} / \mathrm{kg}$ three times the standard deviation of the replicates and LOQ calculated as $0.043 \mu \mathrm{g} / \mathrm{kg}$ as ten times the standard deviation of the same replicates [16].

The mean concentrations of the spiked blanks were $0.014 \mu \mathrm{g} / \mathrm{kg}$, and the signal to noise ratio $(S / N)$ was equal to 3.16 (Equation (4)):

$$
S / N=\frac{\bar{x}}{\delta}
$$

where:

$\bar{x}=$ the mean of replicates.

$\delta=$ The standard deviation of the replicates.

\subsubsection{Linearity and Working Range}

Linearity was evaluated in a range of $0-150 \%$ of the analyte concentration. In this range, six evenly spaced calibration standards should be used. Each standard was analysed five times, and measurements carried out in random order.

Linearity is evaluated based on visual inspection plot of residuals, random distribution of residuals about the zero confirm linearity. (Figure 2). The second way for evaluation was F-test (lack-of-fit) [11,18].

Table 6 shows seven independent calibration curves each point carried out five times. The working range was between $0.043 \mu \mathrm{g} / \mathrm{kg}-10 \mu \mathrm{g} / \mathrm{kg}$ with an R-squared equal to 0.9997.

Table 6. Lack-of-fit test calculations for seven calibration points five times.

\begin{tabular}{cccccccc}
\hline Slope & Intercept & $n$ & $p$ & Nominator & Denominator & MSS $_{\text {error }}$ & MSS $_{\text {lof }}$ \\
\hline 0.0316 & 0.0011 & 7 & 5 & 5 & 28 & $1.0 \times 10^{-5}$ & $2.5 \times 10^{-6}$ \\
\hline
\end{tabular}

The $F_{C a l}$-equation was used to ascertain the linearity; If the $\left(F_{C a l}\right)$ is higher than $\left(F_{T a b}\right)$, the model cannot be considered fit for the data. i.e.,

$\mathrm{H}_{0}$ there is no lack of fit (linear).

$\mathrm{H}_{\mathrm{A}}$ there is a lack of fit (nonlinear). Tabulated $F$ value $\left(F_{T a b}\right)$ and calculated $F$ value $\left(F_{\text {Cal }}\right)$ were calculated as per Equation (5). The $F_{C a l}$ value was 0.42 and $F_{T a b}$ was 2.56. Lack of fit is not statistically significant, and $\mathrm{H}_{0}$ hypothesis was accepted.

$$
F_{\text {Cal }}=\frac{M S S_{\text {Lof }}}{M S S_{\text {error }}}
$$

where: 
$M S S_{\text {Lof }}=$ Mean sum of squares due to lack of fit.

$M S S_{\text {error }}=$ The Mean sum of squares of random error.

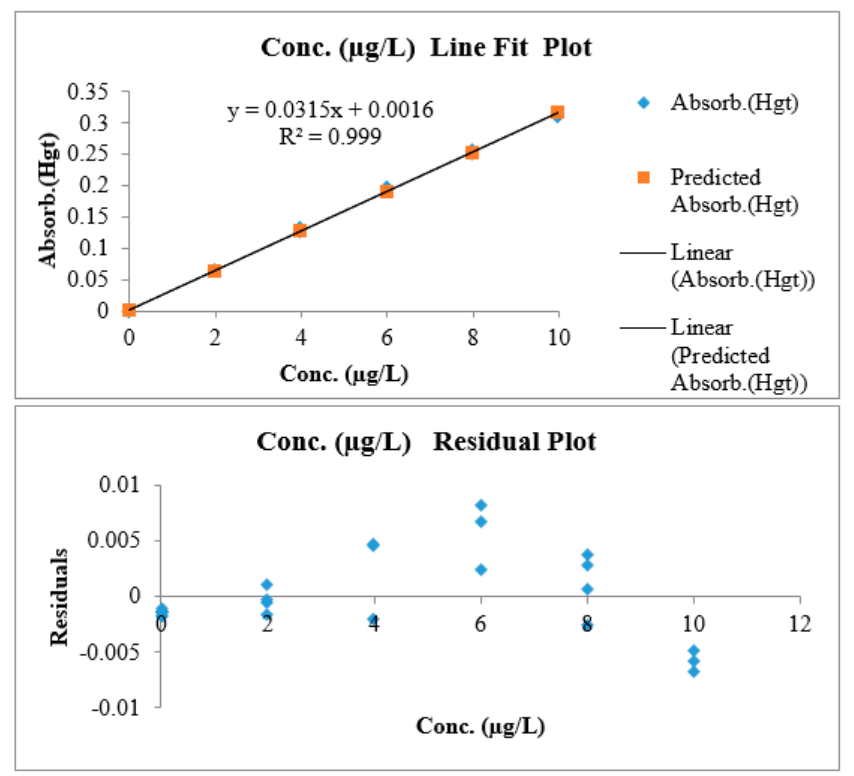

Figure 2. Calibration and residual charts for linearity lack of fit-test.

\subsubsection{Ruggedness}

The ruggedness of the method was examined by changing the principal factors, which have a direct influence on the analysis results such as temperature, digestion time, dilution, sample weight, reagent types, and amounts. Six experiments were performed for two different sample matrices and the Plackett-Burman [19] factorial design analysis for method ruggedness applied to evaluate the effect of changing the five factors (temperature, time, dilution, sample weight, and the amount of reagent added) on the analyte ( $\mathrm{T}-\mathrm{Hg}$ ) result stability (Tables 7 and 8).

Each factor was tested at two levels, high $(+)$ and low $(-)$. Figure 3 shows a comparison between the measured and certified concentration values $(\mathrm{mg} / \mathrm{kg})$ from the two CRMs at different experimental conditions while Tables 9 and 10 represent the statistical analysis (using analysis of variance (ANOVA)) of the two measured and certified mean values.
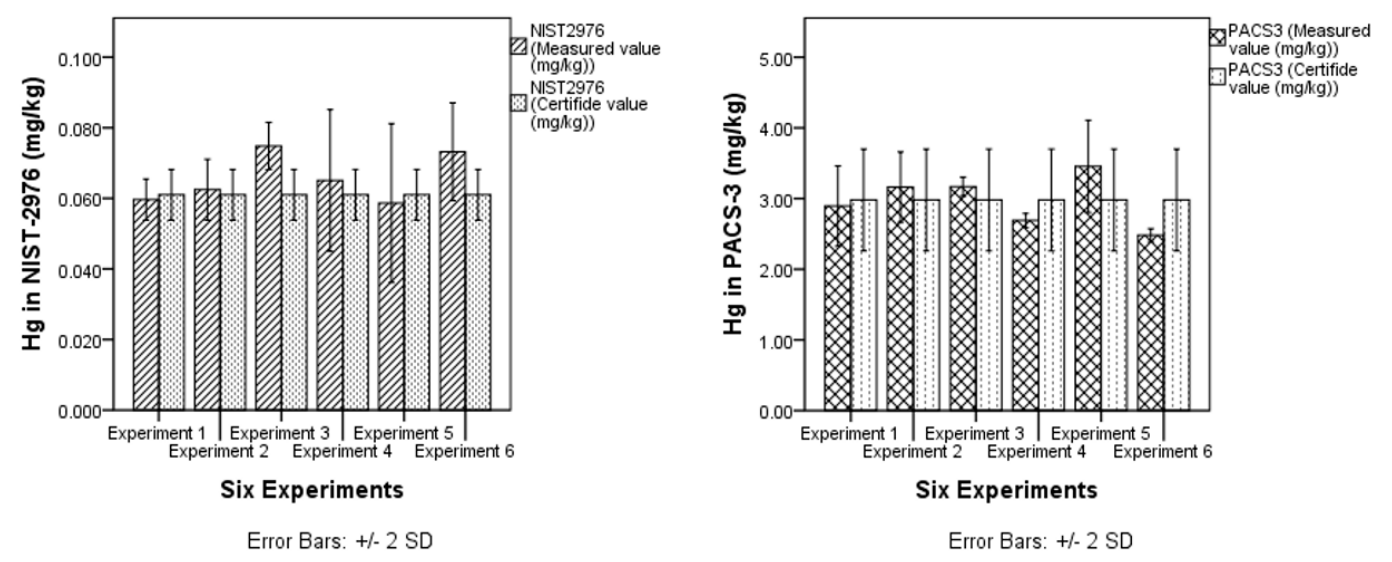

Figure 3. Mean concentrations of two different CRMs (NIST2976, PACS3) compared with its certified values in six experiments at different preparation conditions. 
Table 7. Ruggedness studies of total mercury analyses in marine sediment samples (PACS3) according to Plackett-Burman test.

\begin{tabular}{|c|c|c|c|c|c|c|c|c|c|c|}
\hline Factor & Low Value $(-1)$ & High Value (+1) & Experiment No. & Positive Effect & Negative Effect & Total Effect & Total Effect \% & & & \\
\hline Temp $/{ }^{\circ} \mathrm{C}$ & 100 & 125 & E1 & 3.07 & -2.88 & 0.2 & $7 \%$ & Mean Measured & Ref. Value & Recovery \% \\
\hline Digestion time $/ \mathrm{h}$ & 3 & 12 & E2 & 3.17 & -2.78 & 0.39 & $13 \%$ & Values (mg/kg) & $(\mathrm{mg} / \mathrm{kg})$ & Recovery \% \\
\hline Dilution volume $/ \mathrm{mL}$ & 50 & 100 & E3 & 3.17 & -2.78 & 0.39 & $13 \%$ & & & \\
\hline Sample wt./g & 0.1 & 0.2 & E4 & 2.69 & -3.26 & -0.57 & $-19 \%$ & & & \\
\hline Reagents $\left(\mathrm{HNO}_{3}+\mathrm{H}_{2} \mathrm{SO}_{4}\right) \mathrm{mL}$ & $3+5$ & $6+10$ & E5 & 2.85 & -3.1 & -0.26 & $-9 \%$ & 2.97 & 2.98 & 99 \\
\hline
\end{tabular}

Table 8. Ruggedness studies of total mercury analysis in biota samples (NIST2976) according to Plackett-Burman test.

\begin{tabular}{|c|c|c|c|c|c|c|c|c|c|c|}
\hline Factor & Low Value $(-1)$ & High Value $(+1)$ & Experiment No. & Positive Effect & Negative Effect & Total Effect & Total Effect \% & & & \\
\hline Temp $/{ }^{\circ} \mathrm{C}$ & 100 & 125 & E1 & 0.07 & -0.09 & -0.03 & $-0.90 \%$ & Mean Measured & Ref. Value & Recovery \% \\
\hline Digestion time $/ \mathrm{h}$ & 3 & 12 & E2 & 0.08 & -0.08 & -0.01 & $-0.30 \%$ & Values (mg/kg) & $(\mathrm{mg} / \mathrm{kg})$ & Recovery \% \\
\hline Dilution volume $/ \mathrm{mL}$ & 50 & 100 & E3 & 0.08 & -0.08 & 0 & $0.10 \%$ & & & \\
\hline Sample wt./g & 0.1 & 0.2 & E4 & 0.08 & -0.08 & 0 & $-0.20 \%$ & & & \\
\hline Reagents $\left(\mathrm{HNO}_{3}+\mathrm{H}_{2} \mathrm{SO}_{4}\right) \mathrm{mL}$ & $3+5$ & $6+10$ & E5 & 0.07 & -0.09 & -0.01 & $-0.50 \%$ & 0.065 & 0.061 & 107 \\
\hline
\end{tabular}


Table 9. One-way analysis of variance (ANOVA) analysis results within biota CRM (NIST2976).

\begin{tabular}{cccccc}
\hline & Sum of Squares & df & Mean Square & $\boldsymbol{F}$ & Sig. \\
\hline Between & 0.006 & 5 & 0.001 & 2.442 & 0.095 \\
Groups & 0.006 & 12 & 0.000 & & \\
Within Groups & 0.012 & 17 & & & \\
Total & & & & \\
\hline
\end{tabular}

Table 10. One-way ANOVA analysis results within sediment CRM (PACS-3).

\begin{tabular}{cccccc}
\hline & Sum of Squares & df & Mean Square & $\boldsymbol{F}$ & Sig. \\
\hline Between & 0.370 & 5 & 0.074 & 2.213 & 0.121 \\
Groups & 0.401 & 12 & 0.033 & & \\
Within Groups & 0.771 & 17 & & & \\
Total & & & & \\
\hline
\end{tabular}

\section{Estimation of the Measurement Uncertainty (Quantifying Uncertainty in Analytical Measurement)}

Relative uncertainty is expressed as a relative standard deviation [20] and is equal to absolute error divided by the measured value. The quality of an analytical result is governed by measurement uncertainty, which defines an interval associated with the measured value, defining where this value lies with some probability. Similarly, expanded uncertainty is considered for Type-A and Type-B evaluation of uncertainty to estimate the main resources of error affecting the analysis [20]. Type-A based on statistical analysis of standard deviation of the mean replicates $\left(S_{\bar{x}}\right)$ Equation (6).

$$
S_{\bar{x}}=\frac{s}{\sqrt{n}}
$$

It covers CRM calibration standard repeatability uncertainty. Type-B evaluates all other non-statistical analysis, and it covers glassware uncertainty, equipment uncertainty, reagents, CRM and laboratory conditions uncertainties. Table 11 represents Type-A and Type-B uncertainties at confidence interval of $95 \%(k=2)$. The relative standard uncertainties were divided by the divisor (probability distribution factor) before calculating the combined uncertainty. Combined uncertainty $(u)$ was calculated as a sum squared of standard uncertainties from Equation (7). The relative expanded uncertainty $(U)$ was calculated as $2 \%$ by using Equation (8) at $95 \%$ confidence interval $(k=2)$ (Table 11 ).

$$
u_{c}=\sqrt{\sum u_{R}^{2}}
$$

where: $u_{R}=$ Relative standard uncertainty.

$$
U=(k \times u) \times 100
$$


Table 11. Combined and relative expanded uncertainty calculations based on Type A and B evaluation.

\begin{tabular}{|c|c|c|c|c|c|c|c|c|}
\hline Source of Uncertainty & Type & Measured Value & Error \pm & Unit & $u_{\text {Relative }}$ & Probability Distribution & Divisor & Squared Standard Uncertainty $\left(u^{2}\right)$ \\
\hline Repeatability of prepared $0.6 \mu \mathrm{g} / \mathrm{L} \mathrm{CRM}$ & A & $6 \times 10^{-4}$ & $5.5 \times 10^{-6}$ & $\mathrm{mg} / \mathrm{L}$ & $9.2 \times 10^{-3}$ & Normal, 1s & 1 & $8.5 \times 10^{-5}$ \\
\hline Chemical Reagents purity & B & 1.00 & $5.0 \times 10^{-3}$ & & $5.0 \times 10^{-3}$ & Rectangular & 1.73 & $8.4 \times 10^{-6}$ \\
\hline Pipette $1 \mathrm{~mL}$ repeatability & A & $1.0 \times 10^{-3}$ & $7.8 \times 10^{-8}$ & $\mathrm{~L}$ & $7.8 \times 10^{-5}$ & Normal, 1s & 1 & $6.6 \times 10^{-9}$ \\
\hline Temperature effect on Pipette $1 \mathrm{~mL}$ Volume & B & $1.0 \times 10^{-3}$ & $4.1 \times 10^{-7}$ & $\mathrm{~L}$ & $4.1 \times 10^{-4}$ & Rectangular & 1.73 & $5.6 \times 10^{-8}$ \\
\hline Calibration st certificate uncertainty of pipette $1 \mathrm{~mL}$ & B & $1.0 \times 10^{-3}$ & $3.4 \times 10^{-6}$ & $\mathrm{~L}$ & $3.4 \times 10^{-3}$ & Triangular & 2.45 & $1.9 \times 10^{-6}$ \\
\hline Measuring flask $1 \mathrm{~mL}$ repeatability & A & $5.0 \times 10^{-2}$ & $4.3 \times 10^{-6}$ & $\mathrm{~L}$ & $8.6 \times 10^{-5}$ & Normal, 1s & 1 & $7.4 \times 10^{-9}$ \\
\hline Temperature effect on flask $50 \mathrm{~mL}$ Volume & B & $5.0 \times 10^{-2}$ & $2.0 \times 10^{-5}$ & $\mathrm{~L}$ & $4.1 \times 10^{-4}$ & Rectangular & 1.73 & $5.6 \times 10^{-8}$ \\
\hline Uncertainty of flask $50 \mathrm{~mL}$ & B & $5.0 \times 10^{-2}$ & $6.0 \times 10^{-5}$ & $\mathrm{~L}$ & $1.2 \times 10^{-3}$ & Triangular & 2.45 & $2.4 \times 10^{-7}$ \\
\hline Concentration of the calibration standard & B & 1001 & 2 & $\mathrm{mg} / \mathrm{L}$ & $2.0 \times 10^{-3}$ & Normal, 2s & 2 & $1.0 \times 10^{-6}$ \\
\hline Tare weight repeatability & A & 100 & $3.7 \times 10^{-3}$ & $\mathrm{mg}$ & $3.7 \times 10^{-5}$ & Normal, 1s & 1 & $1.3 \times 10^{-9}$ \\
\hline Gross weight repeatability & A & 100 & $3.7 \times 10^{-3}$ & $\mathrm{mg}$ & $3.7 \times 10^{-5}$ & Normal, 1s & 1 & $1.3 \times 10^{-9}$ \\
\hline Balance linearity contribution (gross weight) & B & 100 & 0.1 & $\mathrm{mg}$ & $1.0 \times 10^{-3}$ & Rectangular & 1.73 & $3.3 \times 10^{-7}$ \\
\hline Balance linearity contribution (tare weight) & B & 100 & 0.1 & $\mathrm{mg}$ & $1.0 \times 10^{-3}$ & Rectangular & 1.73 & $3.3 \times 10^{-7}$ \\
\hline Balance readability (gross weight) & B & 100 & 0.01 & $\mathrm{mg}$ & $1.0 \times 10^{-4}$ & Rectangular & 1.73 & $3.3 \times 10^{-9}$ \\
\hline Balance readability (tare weight) & B & 100 & 0.01 & $\mathrm{mg}$ & $1.0 \times 10^{-4}$ & Rectangular & 1.73 & $3.3 \times 10^{-9}$ \\
\hline Combined standard $u_{c}$ & 0.0098 & & & & & & & \\
\hline Expanded $U$ at $95 \%$ confidence interval $(k=2)$ & $2.0 \%$ & & & & & & & \\
\hline
\end{tabular}




\section{Validation Characteristics Evaluation}

Laboratories must ensure that all data they provide is of recognised quality. One aspect is the use of method validation and its evaluation. The typical steps for of a new test method validation include selectivity, trueness, precision, recovery, etc. The section below details the performed validation criteria (Table 12). Selectivity is the degree to which a method can quantitatively select a distinct analyte in the presence of other analytes that may interfere with our spectrum; two distinct peaks were observed from the CRMs, for low and high levels of $\mathrm{T}-\mathrm{Hg}$ with no interference from other constituents within the CRMs.

Trueness assesses the closeness of the results obtained from the certified value.

Within our analysed results, the data obtained a relative bias of (4-9\%), with acceptance criteria of $\pm 10 \%$. The data was also subjected to a zeta score analysis with results of $(0.4-1.0)$ with acceptance criteria of not more than 2 . The recovery acceptance criteria indicating a $\pm 10 \%$ of the reference value [21] has also been met. Our result recovery ranged from $96-96.4 \%$.

Precision, which included both repeatability and intermediate precision, was evaluated using RSD from five replicates at three different levels $(0.2,2,8 \mu \mathrm{g} / \mathrm{L})$, with results of 5,2 and $1 \%$ for repeatability. Intermediate precision was evaluated using RSD from nine CRM (PACS3 \& NIST2976) replicates producing 5.44 and $4.80 \%$. Limit of detection and quantitation was calculated using multiples of standard deviation [16,22]. Our results produced LOD of $0.010 \mu \mathrm{g} / \mathrm{kg}$, while the LOQ was calculated as $0.043 \mu \mathrm{g} / \mathrm{kg}$. Signal to noise ratio for spiked samples should occur typically between 2.5 to 10 [16,23], our $S / N$ was calculated as 3.16 .

Linearity was assessed using lack-of-fit test [18]; employing a mean of the sum of squares [22] and an $F$-test $\left(\left(F_{\mathrm{Cal}}\right)\right.$ and $\left.\left(F_{T a b}\right)\right)$ to examine the criteria acceptance.

As the obtained $\left(F_{C a l}=0.42\right)$ is less than $\left(F_{T a b}=2.56\right)$, we accept the null hypothesis and the calibration curve was linear.

Ruggedness was assessed by changing some essential factors that have a bearing on the analysis: such as temperature, digestion time, dilution volume, sample weight and reagents volumes, and employing the Plackett-Burman test and an ANOVA to evaluate the extent to which these variations affect the method. The results from the one-way ANOVA test showed that there are no significant variations between six experimental method groups for the two types of CRMs $(p>0.05)$ at confidence interval $95 \%$ illustrating that this method is robust under varying conditions.

Measurement uncertainty estimation is calculated from Equations (7) and (8). This estimation takes into account all the probable experimental errors. Table 11 shows all uncertainty in the in-house calibration and sample measurement. Our data point to a combined standard uncertainty of 0.0098 with an expanded uncertainty of $2 \%$. The expanded uncertainty has been used as a real confidence limit for each measurement for the proposed method. 
Table 12. Fulfil acceptance criteria for all validation characteristics.

\begin{tabular}{|c|c|c|c|c|}
\hline Parameter & Methodology & Acceptance Criteria & Results & Fulfil the Acceptance Criteria! \\
\hline Selectivity & A specific and sharp peak of $\mathrm{Hg}$ produced during $\mathrm{CRM}$ analysis with no interferences & No interferences with the analyte peak. & Complies & Yes \\
\hline Trueness & Relative bias was calculated for ten repeated CRMs & $\begin{array}{l}\text { Relative bias shall not lie outside the limit of } \pm 10 \% \text {, and } \\
\text { Zeta score shall less than or equal } 2 \text { to be satisfactory }\end{array}$ & Complies & Yes \\
\hline Recovery & Two CRMs were used to calculate Recovery $\%$ = Measured value/Reference value. & $\pm 10 \%$ of the reference value & Complies & Yes \\
\hline Precision & Repeated CRMs through one day of analysis and intermediate resection over a long time. & Relative standard deviation (RSD) shall not exceed 10\% & Complies & Yes \\
\hline $\begin{array}{l}\text { Limit of Detection and Limit } \\
\text { of Quantitation }\end{array}$ & $\begin{array}{l}\text { Replicates of low-level concentration CRM matrix used to calculate SD ( } \sigma) \text {. Calculate } \\
S / N \text { ratio }\end{array}$ & 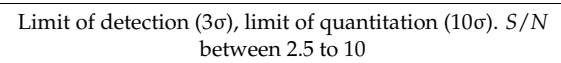 & Complies & Yes \\
\hline Linearity: & Independent calibration curves signal used to calculate $\left(F_{T a b}\right)$ and $\left(F_{C a l}\right)$. & Lack of fit test (Linear if $F_{\mathrm{Cal}}<F_{\mathrm{Tab}}$ ) & Complies & Yes \\
\hline Range & $\begin{array}{l}\text { The concentration interval over which linearity and accuracy are obtained and yields a } \\
\text { precision of } \leq 3 \% \mathrm{RSD} \text {. }\end{array}$ & N/A & Complies & N/A \\
\hline Robustness & $\begin{array}{l}\begin{array}{l}\text { Various conditions tested using Placket-Burman test for experimental design ruggedness. } \\
\text { One-way ANOVA }\end{array}\end{array}$ & $\begin{array}{l}\text { One-way ANOVA was used as statistical acceptance } \\
\text { criteria of robustness at } 95 \% \text { confidence interval }\end{array}$ & Complies & Yes \\
\hline Uncertainty of measurement & $\begin{array}{l}\text { Expanded Uncertainties were considered for in-house Calibration curve }\left(U_{C a l)}\right) \text { and } \\
\text { sample measurement }\left(U_{\text {measu }}\right) \text { to estimate the uncertainty from the main resources } \\
\text { affecting the method. }\end{array}$ & $\mathrm{U}=k^{*} u \%$ & N/A & - \\
\hline
\end{tabular}




\section{Conclusions}

A sensitive and accurate analytical method for validation of total- $\mathrm{Hg}$ in a wide range of environmental matrices was validated according to the IUPAC and Eurachem Guidelines.

The method developed displayed a broad dynamic range and low detection limit $(>0.1 \mu \mathrm{g} / \mathrm{kg})$ without the need for extensive sample preparation. The HotBlock digestion protocol utilised minor amounts of $\mathrm{HNO}_{3}, \mathrm{H}_{2} \mathrm{SO}_{4}$, and $\mathrm{HF}$ in a closed Teflon tube, thus reducing analyte loss and also reducing the risk of contamination. The preparation process was followed by CV AAS analysis. The obtained results were accurate and precise (Recovery $>90 \%$, RSD $\leq 5 \%$ ) when compared to the US-EPA method 3052 and 7474 when employed in the same samples.

Author Contributions: A.A.E. and H.M.H. wrote the article. H.A.A. contributed to the analysis of data and experimental work with A.A.E., Z.K.G. and A.A. have carried out a critical revision and submitted the article. K.E. contributed to the data interpretation. A.E. and S.A.-M. participated in reviewing the article.

Funding: This research received no external funding.

Acknowledgments: We would like to thank Hamad Al Kawari Director of the ESC, for his support during this project. Our appreciation also goes to Hajer Al Niami (Technical Manager) for her assistance and facilitation of these experiments.

Conflicts of Interest: The authors declare that there is no conflict of interest in the article.

\section{References}

1. Risher, J.F.; Amler, S.N. Mercury exposure: Evaluation and intervention. The inappropriate use of chelating agents in the diagnosis and treatment of putative mercury poisoning. Neurotoxicology 2005, 26, 691-699. [CrossRef] [PubMed]

2. Kopyc, E.B.E.; Pyrzysnska, K.; Garbos, S. Determination of Mercury by Cold-Vapor Atomic Absorption Spectrometry with Preconcentration on a Gold-Trap. Anal. Sci. 2000, 16, 1309-1312. [CrossRef]

3. Drennan-Harris, L.R.; Wongwilawan, S.; Tyson, J.F. Trace determination of total mercury in rice by conventional inductively coupled plasma mass spectrometry. J. Anal. At. Spectrom. 2013, 28, 259-265. [CrossRef]

4. Nascimento Neto, A.P.; Costa, L.C.; Kikuchi, A.N.; Furtado, D.M.; Araujo, M.Q.; Melo, M.C. Method validation for the determination of total mercury in fish muscle by cold vapour atomic absorption spectrometry. Food Addit. Contam. Part A 2012, 29, 617-624. [CrossRef] [PubMed]

5. Mercury Instruments. AULA-254 Gold-Mercury Instruments-PDF Catalogue I Technical Documentation I Brochure. Available online: http://pdf.directindustry.com/pdf/mercury-instruments/aula-254-gold/ 187731-692409-_5.html (accessed on 20 August 2018).

6. Tobergte, D.R.; Curtis, S. Microwave assisted acid digestion of sileceous and organically based matrices. J. Chem. Inf. Model. 2013, 53, 1689-1699.

7. USEPA. Mercury in Sediment and Tissue Samples by Atomic Fluorescence Spectrometry; USEPA: Washington, DC, USA, 2007; pp. 1-19.

8. O'Kelly, B.C. Oven-Drying Characteristics of Soils of Different Origins. Dry. Technol. 2007, 23, 1141-1149. [CrossRef]

9. Obi, O.F.; Ezeoha, S.L.; Egwu, C.O. Evaluation of air oven moisture content determination procedures for pearl millet (Pennisetum glaucum L.). Int. J. Food Prop. 2016, 19, 454-466. [CrossRef]

10. Eurachem. Guide to Quality in Analytical Chemistry an Aid to Accreditation; Eurachem: Middlesex, UK, 2016.

11. Thompson, M.; Ellison, S.L.R.; Wood, R. Harmonized guidelines for single-laboratory validation of methods of analysis. Pure Appl. Chem. 2002, 74, 835-855. [CrossRef]

12. USEPA. Mercury (Manual Cold Vapor Technique); USEPA: Washington, DC, USA, 1974; pp. $2-7$.

13. USEPA. Method 245.1: Determination of Mercury in Water by Cold Vapor Atomic Absorption Spectrometry; USEPA: Washington, DC, USA, 1994; Volume 2, pp. 1-18.

14. Murphy, J.; Jones, P.; Hill, S.J. Determination of total mercury in environmental and biological samples by flow injection cold vapour atomic absorption spectrometry. Spectrochim. Acta Part B At. Spectrosc. 1996, 51, 1867-1873. [CrossRef] 
15. USEPA. EPA Method 7473 (SW-846): Mercury in Solids and Solutions by Thermal Decompostion, Amalgamation, and Atomic Absorption Spectrophotometry; USEPA: Washington, DC, USA, 1998.

16. Eurachem. The Fitness for Purpose of Analytical Methods; Eurachem: Middlesex, UK, 2014.

17. University of Tartu. Repeatability, Intermediate Precision and Reproducibility. Available online: https: / / sisu.ut.ee/1cms_method_validation/41-precision-trueness-accuracy (accessed on 26 June 2018).

18. Miller, F.R.; Neill, J.W. Lack of fit tests for linear regression models with many predictor variables using minimal weighted maximal matchings. J. Multivar. Anal. 2016, 150, 14-26. [CrossRef]

19. Analytical Methods Committee. Experimental design and optimisation (4): Plackett-Burman designs. Anal. Methods 2013, 5, 1901-1903. [CrossRef]

20. Citac and Eurachem. Quantifying Uncertainty in Analytical Measurement, 2nd ed.; Citac and Eurachem: London, UK, 2000.

21. NMKL. Guide in Validation of Alternative Proprietary Chemical Methods. Available online: http://www. aoac.org/aoac_prod_imis/AOAC_Docs/ISPAM/3.9NordValprotocolproprietarychemicalanalysis.pdf (accessed on 26 June 2018).

22. Kruve, A.; Rebane, R.; Kipper, K.; Oldekop, M.-L.; Evard, H.; Herodes, K.; Ravio, P.; Leito, I. Tutorial review on validation of liquid chromatography-mass spectrometry methods: Part II. Anal. Chim. Acta 2015, 870, 8-28. [CrossRef] [PubMed]

23. Ripp, J. Analytical Detection Limit Guidance and Laboratory Guide for Determining Method Detection Limits; Wisconsin Department of Natural Resources: Madison, WI, USA, 1996.

(C) 2018 by the authors. Licensee MDPI, Basel, Switzerland. This article is an open access article distributed under the terms and conditions of the Creative Commons Attribution (CC BY) license (http:/ / creativecommons.org/licenses/by/4.0/). 